\title{
Physician attitudes toward the use of fecal microbiota transplantation for the treatment of recurrent Clostridium difficile infection
}

\author{
Jonathan S Zipursky MD¹, Tivon I Sidorsky MD MBA², Carolyn A Freedman MD³, \\ Misha N Sidorsky $\mathrm{AB}^{4}$, Kathryn B Kirkland $\mathrm{MD}^{5}$
}

\begin{abstract}
JS Zipursky, TI Sidorsky, CA Freedman, MN Sidorsky, KB Kirkland. Physician attitudes toward the use of fecal microbiota transplantation for the treatment of recurrent Clostridium difficile infection. Can J Gastroenterol Hepatol 2014;28(6):319-324.
\end{abstract}

BACKGROUND: Fecal microbiota transplantation (FMT) is a safe and effective, yet infrequently used therapy for recurrent Clostridium difficile infection (CDI).

OBJECTIVE: To characterize barriers to FMT adoption by surveying physicians about their experiences and attitudes toward the use of FMT.

METHODS: An electronic survey was distributed to physicians to assess their experience with CDI and attitudes toward FMT.

RESULTS: A total of 139 surveys were sent and 135 were completed, yielding a response rate of $97 \%$. Twenty-five (20\%) physicians had treated a patient with FMT, 10 (8\%) offered to treat with FMT, nine (7\%) referred a patient to receive FMT, and $83(65 \%)$ had neither offered nor referred a patient for FMT. Physicians who had experience with FMT (performed, offered or referred) were more likely to be male, an infectious diseases specialist, $>40$ years of age, fellowship trained and practicing in an urban setting. The most common reasons for not offering or referring a patient for FMT were: not having 'the right clinical situation' (33\%); the belief that patients would find it too unappealing (24\%); and institutional or logistical barriers $(23 \%)$. Only $8 \%$ of physicians predicted that the majority of patients would opt for FMT if given the option. Physicians predicted that patients would find all aspects of the FMT process more unappealing than they would as providers.

CONCLUSIONS: Physicians have limited experience with FMT despite having treated patients with multiple recurrent CDIs. There is a clear discordance between physician beliefs about FMT and patient willingness to accept FMT as a treatment for recurrent CDI.

Key Words: Clostridium difficile infection; Fecal microbiota transplantation; Fecal transplant; Physician attitudes; Shared decision making

Clostridium difficile infection (CDI) is an inflammatory diarrheal illness frequently associated with antibiotic use and characterized by disruptions in the normal intestinal microbiota (1). In recent years, CDIs have become more frequent, severe and refractory to therapy (2-9). It is estimated that $10 \%$ to $35 \%$ of patients treated with standard antibiotic therapy will progress to develop a recurrence (10-12). Up to $65 \%$ of patients treated with antibiotics for recurrent CDI will progress to develop a chronic, recurring form of the disease $(13,14)$.

Fecal microbiota transplantation (FMT) has demonstrated significant value as a therapy for recurrent CDI. A systematic review found

\author{
Les attitudes des médecins envers l'utilisation de la \\ transplantation fécale pour le traitement de \\ l'infection récurrente à Clostridium difficile
}

HISTORIQUE : La transplantation fécale (TF) est un traitement sécuritaire et efficace, mais peu utilisé pour soigner l'infection à Clostridium difficile (ICD) récurrente.

OBJECTIF : Caractériser les obstacles à l'adoption de la TF au moyen d'un sondage auprès des médecins sur leurs expériences et leurs attitudes envers l'utilisation de ce traitement.

MÉTHODOLOGIE : Un sondage électronique a été distribué aux médecins pour évaluer leur expérience de l'ICD et leurs attitudes envers la TF.

RÉSULTATS : Au total, 139 sondages ont été envoyés et 135 ont été remplis, pour un taux de réponse de $97 \%$. Vingt-cinq médecins (20 \%) avaient traité un patient par TF, dix (8\%) avaient offert de le faire, neuf $(7 \%)$ avaient aiguillé un patient en vue d'une TF et $83(65 \%)$ n'avaient ni offert la TF ni aiguillé le patient pour qu'il la reçoive. Les médecins qui avaient l'expérience de la TF (effectuée, offerte ou aiguillée) étaient plus susceptibles d'être de sexe masculin, d'être spécialisés en infectiologie, d'avoir plus de 40 ans, de détenir un postdoctorat et d'exercer en milieu urbain. Les principales raisons de ne pas offrir une TF ou de ne pas aiguiller un patient pour qu'il la reçoive étaient de ne pas être dans « la bonne situation clinique » (33\%), de penser que les patients la trouveraient trop désagréable (24\%) et de se heurter à des obstacles logistiques ou posés par l'établissement (23\%). Seulement $8 \%$ des médecins prédisaient que la majorité des patients opteraient pour la TF si on la leur offrait. Les médecins prédisaient que les patients trouveraient tous les aspects du processus de TF plus désagréable qu'eux-mêmes à titre de dispensateurs.

CONCLUSIONS : Les médecins avaient une expérience limitée de la TF, même s'ils avaient traité des patients ayant de multiples ICD récurrente. On constate une divergence claire entre les croyances des médecins au sujet de la TF et la volonté des patients à l'accepter comme traitement des ICD récurrentes.

\footnotetext{
${ }^{1}$ Faculty of Medicine, Geisel School of Medicine at Dartmouth, Hanover, New Hampshire; ${ }^{2}$ Department of Dermatology, University of California,

San Francisco, San Francisco, California, USA; ${ }^{3}$ University of Toronto Faculty of Medicine, Toronto, Ontario; ${ }^{4}$ Dartmouth College, Hanover;

${ }^{5}$ Section of Infectious Diseases and International Health, Dartmouth-Hitchcock Medical Center, Lebanon, New Hampshire, USA

Correspondence: Dr Jonathan S Zipursky, Department of Medicine, University of Toronto, St Michael's Hospital, 30 Bond Street, Toronto, Ontario M5B 1W8.

Telephone 416-864-6060, e-mail jonathan.zipursky@mail.utoronto.ca

Received for publication January 12, 2014. Accepted February 7, 2014
}

that $92 \%$ of patients treated with FMT for CDI or pseudomembranous colitis experienced rapid resolution of infection and symptoms (15). More recently, the first randomized controlled trial (RCT) of FMT was stopped early because of the treatment failure rate in the control groups; $94 \%$ of patients with recurrent CDI were cured with FMT, compared with $31 \%$ treated with vancomycin and $23 \%$ treated with vancomycin and sham FMT (gastric lavage) (16).

Despite increasing evidence supporting its safety and efficacy, FMT is infrequently used in medical practice. There is a widely held belief that FMT was seldom used because patients had a strong aversion to 
TABLE 1

Demographics of physician survey respondents $(n=135)$

\begin{tabular}{lc}
\hline Characteristic & \\
\hline Sex & \\
Female & $48(37)$ \\
Male & $82(63)$ \\
Missing data & $5(4)$ \\
Age, years & \\
$20-29$ & $12(9)$ \\
$30-39$ & $52(40)$ \\
$40-49$ & $37(28)$ \\
$50-65$ & $22(17)$ \\
$>65$ & $8(6)$ \\
Missing data & $4(3)$ \\
Level of training & \\
Currently in residency & $20(15)$ \\
Finished residency and did not enter fellowship & $24(18)$ \\
Finished residency and in a fellowship & $10(8)$ \\
Finished fellowship & $77(59)$ \\
Missing data & $4(3)$ \\
Type of specialty (either planning or currently practicing) & \\
Infectious diseases & $45(33)$ \\
General internal medicine & $43(32)$ \\
Gastroenterology & $25(19)$ \\
Other & $18(13)$ \\
Missing data & $4(3)$ \\
Uractice setting & \\
Urban academic hospital & \\
Urban private or group practice & $45(34)$ \\
Suburban academic hospital & $12(9)$ \\
Suburban community hospital & $7(5)$ \\
Suburban private or group practice & $2(2)$ \\
Rural academic hospital & $4(3)$ \\
Rural community hospital & $3(2)$ \\
Rural private or group practice & $52(40)$ \\
Government & $2(2)$ \\
Missing data & $3(2)$ \\
\hline Data presented as $n$ (\%) & $1(1)$ \\
M. & $4(3)$ \\
\hline
\end{tabular}

Data presented as $n(\%)$

the procedure based on its unappealing nature $(4,10,11,14,17,18)$. However, we recently published data suggesting that while patients find many aspects of FMT unappealing, these concerns do not interfere with their willingness to accept it in the setting of recurrent CDI (19). In fact, we found that up to $94 \%$ of patients would be willing to accept FMT as a treatment if it were recommended by their physician (19). These findings suggest that there are other significant barriers to FMT adoption. In the present study, we attempted to characterize these barriers by surveying physicians regarding their experiences with and attitudes toward the use of FMT for recurrent CDI.

\section{Survey development and validation}

\section{METHODS}

An electronic survey was developed using the online program Zoomerang. The survey was intended for physicians only and was distributed electronically between May 2011 and February 2012. It was comprised of five sections: physician experience with CDI; physician treatment patterns for CDI; physician experience with FMT; physician perceptions and attitudes toward FMT; and demographic data. A focus group including gastroenterologists in the Department of Gastroenterology at Dartmouth-Hitchcock Medical Center (DHMC, New Hampshire, USA) reviewed the survey for content and comprehension before distribution.
Physicians were first asked about their experience treating CDI and the volume of patients they currently treat for CDI. They were asked to describe their clinical experience treating both primary and recurrent $\mathrm{CDI}$, and the treatment modalities they most commonly recommend for an initial episode, and for a first, second or third or greater recurrence.

Physicians were then asked about their knowledge of the published literature regarding FMT and their experience with FMT. Physicians were asked a series of questions about reasons for performing or recommending, or not performing or recommending FMT, and methods of performing FMT, if they have performed it.

After reading a summary of published data regarding the epidemiology and clinical outcomes of CDI and the efficacy of various treatment modalities compiled from Centers for Disease Control and Prevention (Georgia, USA) publications (20) and UpToDate (21), physicians rated the degree to which this information was consistent with their previous beliefs. They answered questions about what conditions would need to be met for them to offer FMT as a therapy both for nonfulminant and fulminant recurrent CDI. They then were asked to rate aspects of the FMT procedure on a five-point Likert scale, in which 1 represented "I don't find this unappealing at all"; 3 represented "Very unappealing, but not necessarily prohibitive"; and 5 represented "Definitely unappealing to the point of being prohibitive." Finally, using the same scale, physicians rated the degree to which they believed patients and donors would find aspects of the FMT procedure unappealing.

\section{Study participants and recruitment}

Participants were comprised of a convenience sample of primary care and subspecialty physicians, including those practicing internal medicine, family medicine, infectious diseases and gastroenterology. Surveys were distributed electronically to these physicians at DHMC and Baylor College of Medicine (Texas, USA). Physicians were also recruited through a posting by one of the authors $(\mathrm{KBK})$ on the Emerging Infectious Diseases Network. Participation was voluntary, anonymous and uncompensated. All participants were provided with a general description of the survey before agreeing to participate. To help limit selection bias, the description did not reference FMT.

\section{Ethical issues}

The study protocol was reviewed and exempted by the Dartmouth College Committee for Protection of Human Subjects.

\section{Analysis}

Simple and stratified analyses of the data were performed using SPSS version 20 (IBM Corporation, USA). In some cases, Likert scales were collapsed into two categories for analysis: 'unappealing enough to interfere with acceptability' (scores 4 and 5) versus 'not unappealing enough to interfere with acceptability' (scores 1 to 3 ). The McNemar test was used to compare paired proportions and the $\chi^{2}$ test was used to compare the relationship between categorical variables; $\mathrm{P}<0.05$ was considered to be statistically significant.

\section{RESULTS}

A total of 139 surveys were sent and 135 were completed, yielding a response rate of $97 \%$. Of the respondents reporting demographic information, $82(63 \%)$ were male, 52 (40\%) were between 30 and 39 years of age, and 77 (59\%) had completed a clinical fellowship (Table 1). Of physicians providing medical specialty information $(n=131), 43(33 \%)$ were general internal medicine physicians, 45 (35\%) were infectious disease specialists and $25(19 \%)$ were gastroenterologists. Twenty (15\%) respondents were completing residency training.

Among the participants, $100 \%$ had treated a patient with primary CDI and a first recurrence, $95 \%$ had treated a second recurrence of CDI and $77 \%$ had treated a third or greater recurrence. There were 127 (95\%) physicians who were generally aware of FMT as a treatment modality, 71 (56\%) indicated they were moderately informed about the FMT literature and 31 (24\%) indicated they were very informed about FMT. 
TABLE 2

Physician experience with Clostridium difficile infection (CDI)

\begin{tabular}{lcccc}
\hline & Initial & \multicolumn{3}{c}{ Recurrence } \\
\cline { 3 - 5 } $\begin{array}{l}\text { Recommended } \\
\text { episode } \\
\text { treatment for CDI }\end{array}$ & $\begin{array}{c}\text { First } \\
(\mathbf{n}=135)\end{array}$ & $\begin{array}{c}\text { Second } \\
(\mathbf{n}=129)\end{array}$ & $\begin{array}{c}\text { Third } \\
(\mathbf{n}=105)\end{array}$ \\
\hline PO metronidazole & $116(86)$ & $76(56)$ & $6(5)$ & $3(3)$ \\
PO vancomycin & $28(21)$ & $77(57)$ & $85(66)$ & $34(32)$ \\
IV metronidazole & $13(10)$ & $6(4)$ & $9(7)$ & $7(7)$ \\
Pulsed and tapered & $1(1)$ & $7(5)$ & $55(43)$ & $70(67)$ \\
$\quad$ PO vancomycin & & & & \\
Probiotics & $27(20)$ & $37(27)$ & $40(31)$ & $34(32)$ \\
Rifaximin & $0(0)$ & $0(0)$ & $11(9)$ & $23(22)$ \\
Cholestyramine & $0(0)$ & $1(1)$ & $1(1)$ & $8(8)$ \\
IV immunoglobulins & $0(0)$ & $1(1)$ & $1(1)$ & $8(8)$ \\
Fecal biotherapy & $0(0)$ & $0(0)$ & $3(2)$ & $20(19)$ \\
Other & $10(7)$ & $8(6)$ & $3(2)$ & $11(11)$ \\
Has not treated & $0(0)$ & $0(0)$ & $6(4)$ & $30(22)$ \\
\hline
\end{tabular}

Data presented as $n$ (\%). IV Intravenous; PO Per oral

Physician experience with recurrent CDI and FMT

For an initial or first recurrent episode of CDI, most physicians recommended a course of oral metronidazole $(86 \%)$ or oral vancomycin (21\%). Physicians began recommending FMT for a second or greater recurrent CDI, and 19\% of physicians would consider FMT as treatment for a third or greater recurrence of CDI (Table 2). Twenty-five $(20 \%)$ of the physicians in the sample had treated a patient with FMT, $10(8 \%)$ had offered to treat with FMT but the patient declined, nine (7\%) had referred a patient to receive FMT, and 83 (65\%) had neither offered FMT nor referred for FMT. Physicians who had experience with FMT (performed or offered) were more likely to be male, an infectious diseases specialist, $>40$ years of age, fellowship trained and practicing in an urban setting (Table 3 ). Among the 25 physicians who had performed FMT, $88 \%$ reported that, on average, the patients they treated with FMT had none or one recurrences of CDI after FMT.

Of the $44(33 \%)$ physicians who had performed or offered FMT, or referred for FMT, the most common indication for recommending FMT was a third or greater recurrent CDI (96\% who performed FMT, 90\% who offered but not performed FMT, and 100\% who referred). There were $83(65 \%)$ physicians who had neither offered FMT nor referred for FMT. The three most frequent reasons for not offering FMT or referring for FMT were: not having what they considered to be 'the right clinical situation' (33\%); the belief that patients would find FMT too unappealing (24\%); and institutional or logistical barriers (23\%) (Table 4).

Physician beliefs about FMT

Of 127 respondents, 27 (21\%) indicated that the existing evidence was sufficient for them to recommend FMT routinely for nonfulminant, recurrent CDI; 74 (58\%) and 16 (12\%) indicated that an RCT or formal practice guidelines would be necessary, respectively, and $10(8 \%)$ responded 'other'. For patients experiencing fulminant recurrent CDI, 48 respondents $(38 \%)$ believed that the existing evidence was sufficient for them to recommend FMT, 46 (36\%) indicated the need for an RCT in this population, $24(19 \%)$ believed that practice guidelines were necessary, eight $(6 \%)$ responded 'other' and one $(1 \%)$ responded that under no circumstances would they offer FMT.

After reading a summary of information about CDI and the efficacy of different treatment modalities: 16 (12\%) of 135 respondents indicated that the efficacy of antibiotics for recurrent CDI was much lower than they believed and $15(11 \%)$ that deaths from CDI were much higher than they believed. Among 135 respondents, 31 (23\%) indicated that the reported efficacy of FMT was higher than they believed, $23(17 \%)$ were surprised that there were so few published reports on FMT, and 16 (12\%) believed that RCTs for FMT had already been published.
TABLE 3

Physician characteristics associated with having treated with fecal microbiota transplantation (FMT), or offered or referred patients for FMT

\begin{tabular}{|c|c|c|}
\hline Physician characteristic & $\begin{array}{c}\text { Treated, offered } \\
\text { to treat or referred for } \\
\text { treatment with FMT, } n(\%)\end{array}$ & $\mathbf{P}$ \\
\hline Sex & & 0.02 \\
\hline Female $(n=46)$ & $10(22)$ & \\
\hline Male $(n=78)$ & $34(44)$ & \\
\hline Age, years & & $<0.001$ \\
\hline$<40(n=61)$ & $12(20)$ & \\
\hline$\geq 40(n=64)$ & $32(50)$ & \\
\hline Specialty & & $<0.001$ \\
\hline Infectious diseases $(n=45)$ & $30(67)$ & \\
\hline Non-Infectious diseases $(n=80)$ & $14(18)$ & \\
\hline Level of training & & $<0.001$ \\
\hline Has not completed fellowship $(n=50)$ & $7(14)$ & \\
\hline Has completed fellowship $(n=75)$ & $37(49)$ & \\
\hline Setting of training & & $<0.001$ \\
\hline Urban $(n=61)$ & $28(46)$ & \\
\hline Rural $(n=54)$ & $8(15)$ & \\
\hline
\end{tabular}

\section{TABLE 4}

Reasons given by physicians for not offering fecal microbiota transplantation $(F M T)^{*}(n=83)$

\begin{tabular}{lc}
\hline Reasons for not offering FMT & $\begin{array}{c}\text { Physicians } \\
\text { reporting this } \\
\text { reason, } \mathbf{n} \text { (\%) }\end{array}$ \\
\hline Have not had the right clinical situation ${ }^{\dagger}$ & $27(33)$ \\
Believe that patients will find the concept too & $20(24)$ \\
$\quad$ unappealing & $19(23)$ \\
Institutional barriers (eg, IRB) make it difficult & $15(18)$ \\
I (physicians) find the concept too unappealing & $10(12)$ \\
Do not know enough about it ${ }^{\dagger}$ & $6(7)$ \\
Do not know whom to refer to & \\
Have concerns about the safety of the treatment & $6(7)$ \\
Do not believe it is effective based on data & $3(4)$ \\
Do not believe that I will receive reimbursement & $1(1)$ \\
Other & $10(12)$
\end{tabular}

${ }^{*}$ Respondents were allowed to choose more than one option; †Options added based on free-text responses. IRB Institutional review board

When asked to consider a scenario in which a group of patients with recurrent CDI were fully informed of both the recurrence rates following antibiotic therapy and the reported efficacy and safety of FMT, and then given a choice of FMT or antimicrobial therapy alone, only $10(8 \%)$ of 131 respondents predicted that the majority of informed patients would choose FMT. Fifty-six (43\%) predicted that "a fair number" of patients would choose FMT, 63 (47\%) that only a small number of patients would choose FMT, one (1\%) predicted that all patients would choose FMT and one (1\%) predicted that no patients would choose FMT.

Physicians' rating aspects of the FMT procedure

Physicians rated all aspects of FMT as at least somewhat unappealing (mean score $>2$ ) with the most negative scores associated with administering stool by nasogastric tube (3.2 of 5.0; with $44 \%$ of physicians rating at either a 4 or 5$)$ and collecting, blending and straining the stool specimen ( 3.0 of 5.0 ; with $29 \%$ of physicians rating at either a 4 or 5 ). Among respondents, the least unappealing aspect of the treatment process was administering the stool by colonoscopy (2.0 of 5) (Table 5). While large percentages of providers found various aspects of FMT to 
TABLE 5

Likert rating scale* of physician responses to questions regarding their own views about aspects of fecal microbiota transplatation (FMT) and their predictions about how patients would answer the same questions

\begin{tabular}{|c|c|c|c|c|c|c|c|}
\hline \multirow[b]{2}{*}{ Aspect of FMT } & \multicolumn{3}{|c|}{ Physician responses } & \multicolumn{3}{|c|}{ Physician predictions about patients } & \multirow[b]{2}{*}{$\mathbf{P}$} \\
\hline & $\begin{array}{l}\text { FMT unappealing, } \\
\text { but would consider } \\
\text { (rating } 1,2 \text { or } 3 \text { ) }\end{array}$ & $\begin{array}{l}\text { FMT too } \\
\text { unappealing to } \\
\text { consider } \\
\text { (rating } 4 \text { or } 5 \text { ) }\end{array}$ & $\begin{array}{l}\text { Missing, } \\
\mathrm{n}\end{array}$ & $\begin{array}{l}\text { FMT unappealing, } \\
\text { but would } \\
\text { consider } \\
\text { (rating } 1,2 \text { or } 3 \text { ) }\end{array}$ & $\begin{array}{l}\text { FMT too } \\
\text { unappealing to } \\
\text { consider } \\
\text { (rating } 4 \text { or } 5 \text { ) }\end{array}$ & $\begin{array}{l}\text { Missing, } \\
\mathbf{n}\end{array}$ & \\
\hline $\begin{array}{l}\text { Collecting, blending and transferring stool } \\
\text { specimen }\end{array}$ & $80(70.8)$ & $33(29.2)$ & 22 & $53(45.7)$ & $63(54.3)$ & 19 & $<0.001$ \\
\hline $\begin{array}{l}\text { Cleaning all the required preparation and } \\
\text { delivery equipment }\end{array}$ & $82(74.5)$ & $28(25.5)$ & 25 & $52(44.8)$ & $64(55.2)$ & 19 & $<0.001$ \\
\hline Administering (receiving) the stool via enema & $89(79.5)$ & $23(20.5)$ & 23 & $86(74.8)$ & $29(25.2)$ & 20 & 0.629 \\
\hline $\begin{array}{l}\text { Administering (receiving) the stool via } \\
\text { colonoscopy }\end{array}$ & $86(82.7)$ & $18(17.3)$ & 31 & $82(76.6)$ & $25(23.4)$ & 28 & 0.549 \\
\hline Administering (receiving) the stool via NG tube & $63(55.8)$ & $50(44.2)$ & 22 & $44(38.9)$ & $69(61.1)$ & 22 & 0.002 \\
\hline $\begin{array}{l}\text { The smell and appearance of the stool } \\
\text { throughout the process }\end{array}$ & $82(72.6)$ & $31(27.4)$ & 22 & $57(50.4)$ & $56(49.6)$ & 22 & $<0.001$ \\
\hline Finding a donor & & & & $76(66.7)$ & $38(33.3)$ & 21 & \\
\hline
\end{tabular}

Data presented as $n(\%)$ unless otherwise indicated. ${ }^{*} 1=$ Not unappealing at all; $3=$ Very unappealing but could deal with it; $5=$ Too unappealing to deal with McNemar test was used to compare physician responses to their predictions about patients in the category 'FMT too unappealing to consider' (4,5). $P<0.05$ was considered to be statistically significant. NG Nasogastric

be unappealing to the point of being potentially prohibitive (rating of 4 or 5), no single aspect was deemed prohibitively unappealing by a majority of providers.

When asked to predict how patients and donors would rate potentially unappealing aspects of FMT, physicians predicted that patients and donors would rate all aspects of FMT as at least 'very unappealing, but not necessarily prohibitive' (mean score $>3$ ). Physicians predicted that the most negative scores would be associated with receiving FMT through an nasogastric tube (3.8 of 5.0; 61\% rated either a 4 or 5). Physicians predicted that the least unappealing aspect of FMT for patients/donors would be receiving FMT by colonoscopy (2.8 of 5) or enema (3.0 of 5).

Physicians believed that four aspects of the FMT process would be more unappealing for patients and donors than for providers themselves, and that, in fact, the majority of patients would find them so unappealing that they would interfere with acceptability (ie, rated as 4 or 5). Physicians predicted that $54 \%$ of patients (versus $29 \%$ of physicians; $\mathrm{P}<0.001$ ) would find collecting, blending and transferring the stool specimen unappealing enough to interfere with acceptability. They predicted $55 \%$ of patients (versus $26 \%$ of physicians; $\mathrm{P}<0.001$ ) would find cleaning all of the required preparation and delivery equipment this unappealing. They predicted that $61 \%$ of patients (versus $44 \%$ of physicians; $\mathrm{P}=0.002$ ) would find administering versus receiving the stool via nasogastric tube this unappealing. Finally physicians predicted $50 \%$ of patients (versus $29 \%$ of physicians; $\mathrm{P}<0.001$ ) would find the smell and appearance of stool throughout the process unappealing enough to interfere with acceptability.

\section{DISCUSSION}

FMT is a safe, effective and seldom-used therapy for recurrent CDI. Editorialists have speculated on likely barriers to FMT adoption by physicians, suggesting that its aesthetically unappealing nature, logistical challenges and a previous lack of efficacy data from RCTs may be among the most common (22). The present study was the first to gather information regsarding barriers directly from physicians. Our study confirms that most physicians lack experience with FMT and offers several possible explanations for the fact that this treatment is still infrequently used, despite the growing CDI epidemic.

Our survey found that while $100 \%$ of the physicians reported treating patients with recurrent CDI, only $20 \%$ have treated a patient with FMT, and most (65\%) have neither offered FMT nor referred for FMT.
Among the $65 \%$ of physicians, $80 \%$ indicated the following three most frequent reasons for not doing so. The most common reason (cited by 27 [33\%] of 83 physicians) was not having encountered what they considered to be an appropriate clinical situation. Of note, all physicians had treated patients with recurrent CDI (100\%, 95\% and $77 \%$ had treated patients with one, two, or three or more recurrences, respectively) and most considered themselves to be familiar with FMT's efficacy and safety in recurrent CDI. Interestingly, of the 27 physicians who reported that they had not encountered an appropriate clinical situation, 25 (96\%) had treated a second recurrent CDI and 15 (56\%) had treated a third or greater recurrent CDI. One possible explanation for this apparent contradiction may be that many physicians are not entirely clear on what may justify an appropriate patient because many also stated that they would need formal practice guidelines to offer FMT to a patient with recurrent CDI. The second most common reason (cited by 24\%) was the belief that patients would find the concept of FMT too unappealing. It appears possible that this belief may have also been ingrained within physicians' conceptualization of what constitutes an appropriate patient, helping to explain their having not encountered such a patient as the most common reason for having not offered FMT or referred for FMT, as discussed above. The third most common reason (cited by $23 \%$ ) was institutional or logistical barriers including the need for institutional review board approval. Notably, $18 \%$ of physicians also cited their own aversion to FMT as a reason for not offering it to patients. Also of note, only one respondent cited concern about reimbursement (Table 4).

Physicians' responses regarding the efficacy and safety of FMT were somewhat inconsistent. Although a majority of physicians indicated that more evidence or practice guidelines would be needed before they would offer FMT to patients, a very small minority cited skepticism about the evidence supporting FMT's effectiveness (4\%) or safety (7\%) as reasons for not offering it. Furthermore, most respondents indicated familiarity with current efficacy and safety data supporting FMT, and few were surprised by the evidence presented. The incongruence of these responses make it difficult to predict what impact the recently published RCT (16) will have on FMT adoption. It may be a necessary, but insufficient, factor in changing practice; significantly increased adoption may require that the more commonly cited reasons for not recommending FMT are also addressed.

Our findings confirm the fact that physicians, similar to patients, find aspects of FMT unappealing. Physicians and patients tend to find 
the same aspects (administering and receiving FMT by nasogastric tube and the need to handle the stool [19]) most unappealing, but interestingly, physicians believe patients will find all aspects of FMT more unappealing than physicians do. Using a recently published survey on patient attitudes toward FMT for comparison (19), physician respondents dramatically overestimated both the intensity of patients' aversion and the degree to which the unappealing nature of FMT would act as a deterrent to patients' willingness to consider the treatment. Less than $10 \%$ of physicians believed that the majority of patients with recurrent CDI would consider FMT if informed about FMT's current safety and efficacy data. However, the patient survey found that up to $94 \%$ of patients would consider FMT, especially if it were recommended by their physician (19). This misperception about patients' receptivity to FMT may be an important and modifiable barrier keeping physicians from recommending this treatment.

Overcoming physician aversion to certain aspects of FMT may also lead to wider use of FMT. In fact, up to $29 \%$ of physicians categorized certain aspects of FMT (particularly those that involved handling and smelling fecal material) as unappealing enough to prevent them from offering the treatment. Creating protocols for reducing the need to contact stool (23) or shifting the handling of stool away from physicians (24) may remove this barrier. Moreover, innovations in preparation of fecal material or even synthetic stool (25) may improve the aesthetics of the procedure and, thus, its acceptance.

Our survey illustrates that logistical issues, including uncertainty about the need for institutional review board approval and the lack of a universally accepted protocol - although standardized protocols do exist (23) - certainly pose additional barriers to FMT. While planning to use enforcement discretion, the recent guidance by the Food and Drug Administration urging physicians to obtain investigational new drug approval before performing FMT (26) may also add some complexity. We are hopeful and optimistic that ongoing communication and collaboration between physician organizations and the Food and Drug Administration, in tandem with additional forthcoming RCT data (27), will soon lead to a reduction in the degree to which these perceived potential logistical complexities limit FMT adoption.

\section{REFERENCES}

1. Kachrimanidou M, Malisiovas N. Clostridium difficile infection: A comprehensive review. Crit. Rev. Microbiol 2011;37:178-87.

2. Bartlett J. Narrative Review: The new epidemic of Clostridium difficileassociated enteric disease. Ann Intern Med 2006;145:758-64.

3. McDonald LC, Owings M, Jernigan DB. Clostridium difficile infection in patients discharged from US short-stay hospitals, 1996-2003. Emerg Infect Dis 2006;12:409-15.

4. Kelly C, LaMont J. Clostridium difficile - more difficult than ever. N Engl J Med 2008;359:1932-40.

5. Gravel D, Miller M, Simor A, et al. Health care-associated Clostridium difficile infection in adults admitted to acute care hospitals in Canada: A Canadian Nosocomial Infection Surveillance Program Study. Clin Infect Dis 2009;48:568-76.

6. Pépin J, Valiquette L, Cossette B. Mortality attributable to nosocomial Clostridium difficile-associated disease during an epidemic caused by a hypervirulent strain in Quebec. CMAJ 2005;173:1037-42.

7. United Kingdom national statistics. Newport, United Kingdom: Office for National Statistics, UK Statistics Authority. $<$ www.statistics.gov.uk> (Accessed September 26, 2012).

8. Pepin J, Alary M-E, Valiquette L, et al. Increasing risk of relapse after treatment of Clostridium difficile colitis in Quebec, Canada. Clin Infect Dis 2005;40:1591-7.

9. Cohen SH, Gerding DN, Johnson S, et al. Clinical practice guidelines for Clostridium difficile infection in adults: 2010 update by the Society for Healthcare Epidemiology of America (SHEA) and the Infectious Diseases Society of America (IDSA). Infect Control Hosp Epidemiol 2010;31:431-55.

10. Nood E Van, Speelman P, Kuijper E, et al. Struggling with recurrent Clostridium difficile infections: Is donor faeces the solution? Euro Surveill 2009;359:1-6.
Although it provides the first systematically collected data on physician attitudes toward FMT, our study was limited in size and scope and may not be generalizable to all practicing physicians. We had relatively fewer female and gastroenterologist respondents. Thus, our stratified analysis of the data according to medical specialty was underpowered. Although the survey was performed before the publication of the first RCT for FMT, a strength of the study was its similarity to the survey used for our tandem patient study (19). In addition, the timing of the survey distribution enabled us to collect physician responses before the publication of our survey of patient attitudes and beliefs (19). Therefore, the physician respondents were not biased by previous knowledge of the patient responses.

The discordance revealed between patient attitudes and willingness to accept FMT and physicians' beliefs that patients will not accept FMT is the most important finding of the two surveys. It suggests that there is an opportunity for more dialogue between physicians and patients about the increasingly rigorous evidence supporting the use of FMT for recurrent CDI and shared decision making regarding whether the unappealing nature of the treatment is a barrier that can be overcome. Technological innovations that can reduce the need to handle stool and further efforts to systematize protocols and eliminate regulatory restrictions may significantly increase the adoption of FMT as well.

ACKNOWLEDGEMENTS: The authors thank the physicians in the Division of Gastroenterology at Dartmouth-Hitchcock Medical Center for their help in reviewing the survey and all of the physicians who voluntarily participated in the survey.

DISCLOSURES: Tivon and Misha Sidorsky have a pending patent related to the field of fecal microbiota transplantation. The other authors have no financial disclosures or conflicts of interest to declare.

FUNDING: This work was supported by a scholarship from the Infectious Disease Society of America (IDSA) 2011 Medical Scholars Program.

11. Bakken JS. Fecal bacteriotherapy for recurrent Clostridium difficile infection. Anaerobe 2009;15:285-9.

12. Huebner ES, Surawicz CM. Treatment of recurrent Clostridium difficile diarrhea. Gastroenterol Hepatol 2006;2:203-8.

13. Pépin J, Routhier S, Gagnon S, et al. Management and outcomes of a first recurrence of Clostridium difficile-associated disease in Quebec, Canada. Clin Infect Dis 2006;42:758-64.

14. Borody TJ, Warren EF, Leis SM, et al. Bacteriotherapy using fecal flora: Toying with human motions. J Clin Gastroenterol 2004;38:475-83.

15. Gough E, Shaikh H, Manges AR. Systematic review of intestinal microbiota transplantation (fecal bacteriotherapy) for recurrent Clostridium difficile infection. Clin Infect Dis 2011;53:994-1002.

16. van Nood E, Vrieze A, Nieuwdorp M, et al. Duodenal infusion of donor feces for recurrent Clostridium difficile. $\mathrm{N}$ Engl J Med 2013;368:407-15.

17. Kahn SA, Gorawara-Bhat R, Rubin DT. Fecal bacteriotherapy for ulcerative colitis: Patients are ready, are we? Inflamm Bowel Dis 2012;18:676-84.

18. Borody TJ, Campbell J. Fecal microbiota transplantation: Current status and future directions. Expert Rev Gastroenterol Hepatol 2011;5:653-5.

19. Zipursky JS, Sidorsky TI, Freedman CA, et al. Patient attitudes toward the use of fecal microbiota transplantation in the treatment of recurrent Clostridium difficile infection. Clin Infect Dis 2012;55:1-7.

20. Clostridium difficile Infection. Centers Dis Control Prev Heal Infect <www.cdc.gov/hai/organisms/cdiff/cdiff_infect.html> (Accessed September 26, 2012).

21. Kelly CP, LaMont J. Clostridium difficile in adults: Treatment. UpToDate. <www.uptodate.com> (Accessed September 26, 2012). 
22. Kelly CP. Fecal microbiota transplantation - an old therapy comes of age. N Engl J Med 2013;368:4745.

23. Bakken JS, Borody T, Brandt LJ, et al. Treating Clostridium difficile infection with fecal microbiota transplantation. Clin Gastroenterol Hepatol 2011;9:1044-9.

24. Silverman MS, Davis I, Pillai DR. Success of self-administered home fecal transplantation for chronic Clostridium difficile infection. Clin Gastroenterol Hepatol 2010;8:471-3.

25. Petrof EO, Gloor GB, Vanner SJ, et al. Stool substitute transplant therapy for the eradication of Clostridium difficile infection: "RePOOPulating" the gut. Microbiome 2013;1:3.
26. Guidance for Industry: Enforcement Policy Regarding Investigational New Drug Requirements for Use of Fecal Microbiota for Transplantation to Treat Clostridium difficile Infection Not Responsive to Standard Therapies. 2013.

$<$ GuidanceComplianceRegulatoryInformation/Guidances/Vaccines/ ucm361379.htm> (Accessed June 26, 2013).

27. Kelly CR, Brandt LJ. Fecal Transplant for Relapsing C. Difficile Infection. ClinicalTrials.gov. <www.clinicaltrials.gov/ct2/show/NCT 01703494 ?term $=$ fecal + transplant + brandt $\&$ rank $=1>$ (Accessed June 26, 2013). 


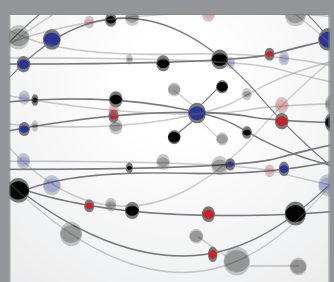

The Scientific World Journal
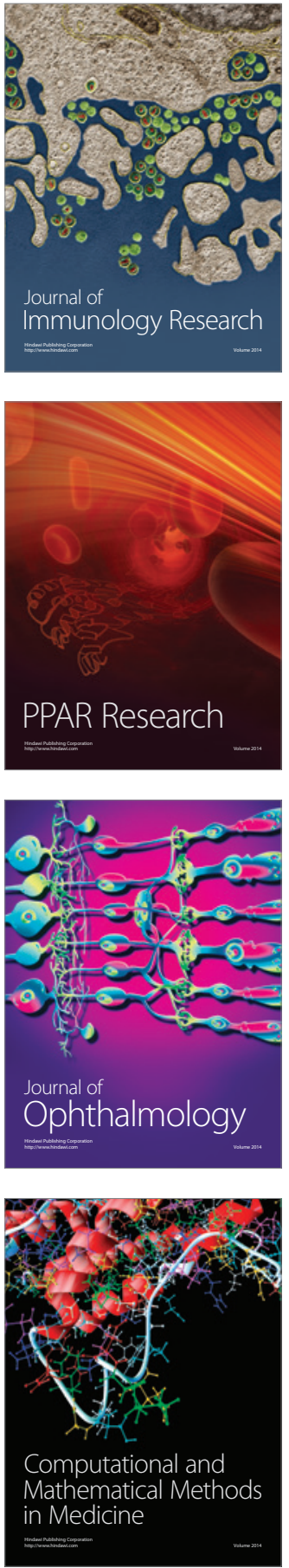

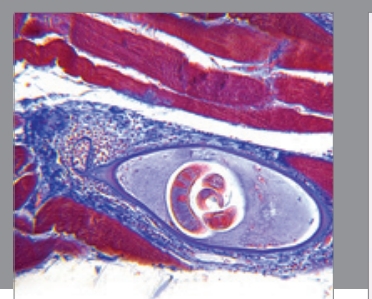

Gastroenterology Research and Practice

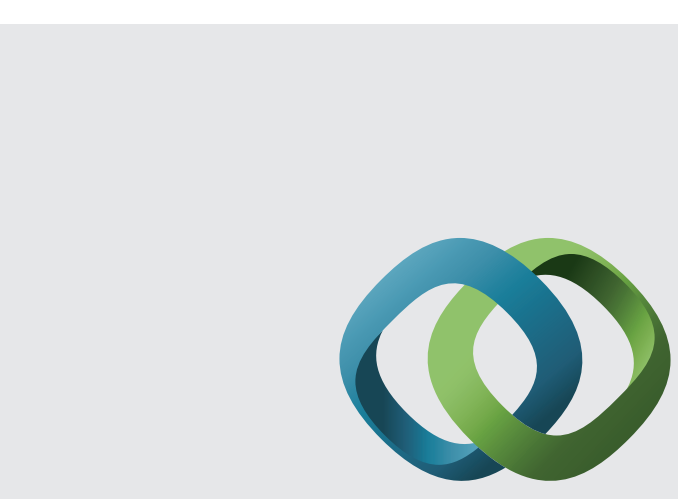

\section{Hindawi}

Submit your manuscripts at

http://www.hindawi.com
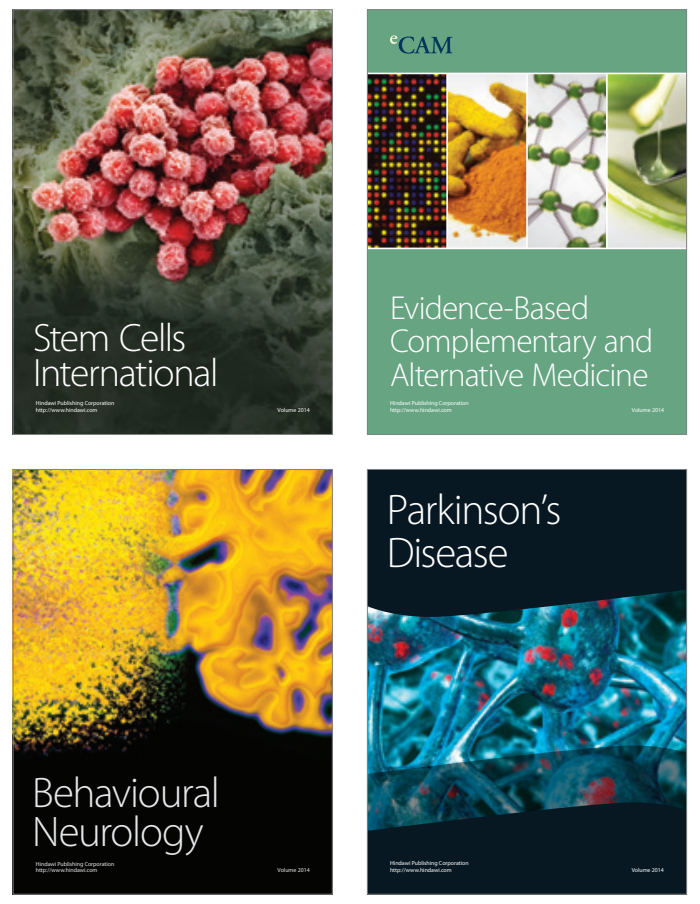
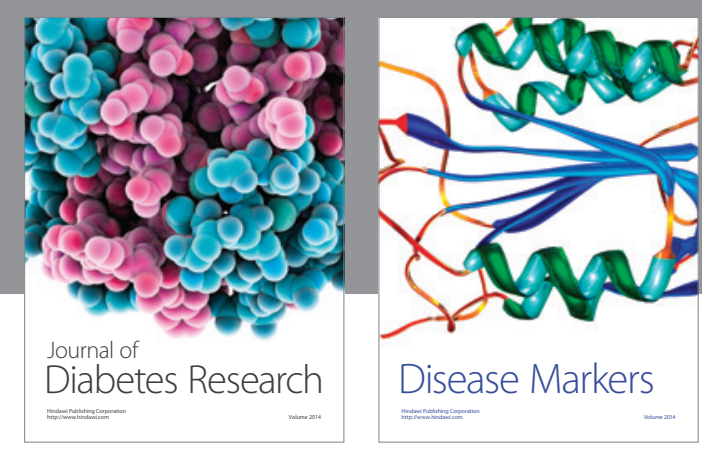

Disease Markers
